\title{
Catching Education Up with Technology: Preparing the Public to Make Informed Choices about Personal Genetics
}

\author{
M. E. Gelbart
}

Director of Program Development and National Initiatives, Personal Genetics Education Project, Harvard Medical School, Boston, MA 02115

\section{Dear Editor:}

As we approach an era in which personal genome sequencing will be inexpensive and rapid enough for routine use in the clinic, genetic information will play an increasingly prominent role in healthcare. Therefore, the fields of personalized medicine and pharmacogenomics seek to utilize personal genetic information to develop individualized diagnostic and therapeutic strategies. For their potentially transformative effects to be fully realized, a public that is informed about genetics is essential.

In their recent article, Dougherty and colleagues (2011) highlight this critical educational need. They demonstrate that statewide standards for genetics education at the high school level are largely inadequate, particularly for concepts related to complex traits, which are fundamental for comprehending the potential and the intricacies of interpreting personal genetic information. This report is alarming, as it is critical that upcoming generations know about the promise of personalized medicine, our current ability to interpret genome sequences, and the limitations of what this information can predict about future health.

To complement the improvements in genetics education recommended by Dougherty and colleagues, our society must also be made aware of the complex ethical, legal, and social implications (ELSI) of the choices we will face. Therefore, the most effective preparation of our society for the benefits

DOI: $10.1187 /$ cbe.11-10-0092

Address correspondence to: M. E. Gelbart (mgelbart@pgEd.med .harvard.edu).

Marnie Gelbart is an employee of the Personal Genetics Education Project (pgEd), a nonprofit educational outreach group at Harvard Medical School. No promotion of the pgEd curriculum to the exclusion of other educational materials should be construed.

(C) 2012 M. E. Gelbart. CBE_Life Sciences Education (c) 2012 The American Society for Cell Biology. This article is distributed by The American Society for Cell Biology under license from the author(s). It is available to the public under an AttributionNoncommercial-Share Alike 3.0 Unported Creative Commons License (http:/ / creativecommons.org/licenses/by-nc-sa/3.0).

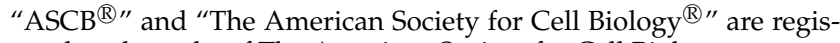
tered trademarks of The American Society for Cell Biology. and challenges of modern genetics should include a comprehensive program addressing the ELSI of personal genetics. To make informed decisions about obtaining and sharing personal genetic information, individuals will also need to consider many complex questions, such as:

- What do you want to learn from your genome sequence? Predictions about your health? Predictions about your behavior?

- Would you ask your family's permission before having your genome analyzed, since it may potentially reveal information about the genetic makeup of your relatives?

- Would a person's genetic predisposition to a disease affect your decision to date that individual?

- How private is your genetic information? How are you protected against genetic discrimination?

As the cost of personal genome sequencing rapidly declines, we must act quickly to integrate these and other important topics into the curriculum. At the Personal Genetics Education Project (pgEd), we suggest that educating high school students offers a cost-effective and comprehensive strategy to broadly reach a generation of young adults who will become independent healthcare consumers just as genome sequencing becomes a low-cost, widely available option.

Issues in personal genetics involve multiple fields, including genetics, ethics, sociology, policy, and health. Determining what students should learn will require interdisciplinary dialogue and will yield opportunities to include units on personal genetics in multiple classrooms, including those of biology, health, social studies, psychology, and law. A program that incorporates ELSI discussions across the curriculum is likely to have the broadest impact, reaching students regardless of their inclination toward science.

Promoting a coordinated national effort to incorporate personal genetics education into high school curricula is precisely our mission at pgEd. Our curriculum is freely available on our website (www.pgEd.org) to help teachers start discussions about personal genetics in their classrooms. We envision that efforts such as these will help to cultivate a 
community of informed individuals prepared to face highly personal choices about their genetic information and therefore optimally poised to benefit from this new era in science and medicine.

\section{REFERENCE}

Dougherty MJ, Pleasants C, Solow L, Wong A, Zhang H (2011). A comprehensive analysis of high school genetics standards: are states keeping pace with modern genetics? CBE Life Sci Educ 10, 318-327. 